International Journal of Current Advanced Research

ISSN: O: 2319-6475, ISSN: P: 2319 - 6505, Impact Factor: SJIF: 5.995

Available Online at www.journalijcar.org

Volume 6; Issue 3; March 2017; Page No. 2687-2690

DOI: http://dx.doi.org/10.24327/ijcar.2017.2690.0077

Research Article

\title{
KNOWLEDGE AND AWARENESS OF ANUG AMONG DENTAL STUDENTS
}

\author{
S.Vignesh., Dhanraj and Suresh
}

Department of prosthodontics, Saveetha Dental College

\section{A R T I C L E I N F O}

\section{Article History:}

Received $12^{\text {th }}$ December, 2016

Received in revised form $6^{\text {th }}$ January, 2017

Accepted $26^{\text {th }}$ February, 2017

Published online $28^{\text {th }}$ March, 2017

\section{Key words:}

ANUG, Debriment

\begin{abstract}
A B S T R A C T
Topic: Knowledge and awareness of ANUG (Acute necrotizing ulcerative gingivitis) among the dental students

Aim : To observe and analyse knowledge of ANUG (Acute necrotizing ulcerative gingivitis) among the students in Dentistry

Objective: To identify the awareness of ANUG in the dental students

Background: ANUG is known as the Acute necrotizing ulcerative gingivitis. It has a common symptoms like pain, bleeding.It is often present on the dental papillae \& marginal gingiva. It causes severe pain during the time of swallowing \& talking.This can be diagnosed only by the clinical findings. The chief diagnosis is the gums does not respond immediately to the conventional treatment. It's common treatment includes Rinsing,improved oral therapy.
\end{abstract}

Reason :The knowledge and awareness levels about ANUG amongst the dental students seems to unclear and this study was initiated to explore this further.

Copyright $@ 2017$ S.Vignesh., Dhanraj and Suresh. This is an open access article distributed under the Creative Commons Attribution License, which permits unrestricted use, distribution, and reproduction in any medium, provided the original work is properly cited.

\section{INTRODUCTION}

Acute necrotizing ulcerative gingivitis (ANUG; colloquially known as trench mouth) is a common, non-contagious infection of the gums with sudden onset. The main features are painful, bleeding gums, and ulceration of inter-dental papillae (the sections of gum between adjacent teeth). This disease, along with necrotizing (ulcerative) periodontitis (NP or NUP) is classified as a necrotizing periodontal disease, one of the seven general types of periodontitis. The often severe gingival pain that characterizes ANUG distinguishes it from the more common chronic periodontitis which is rarely painful. ANUG is the acute presentation of necrotizing ulcerative gingivitis (NUG), which is the usual course the disease takes. If improperly treated or neglected, NUG may become chronic and/or recurrent. The causative organisms are mostly anaerobic bacteria, particularly Fusobacteria and Spirocaete species. Predisposing factors include poor oral hygiene, smoking, malnutrition, psychological stress and immunosuppression (sub-optimal functioning of the immune system). When the attachments of the teeth to the bone are involved, the term NUP is used. Treatment of ANUG is by debridement (although pain may prevent this) and antibiotics (usually metronidazole) in the acute phase, and improving oral hygiene to prevent recurrence.

*Corresponding author: S.Vignesh, Department of prosthodontics, Saveetha Dental College
Although the condition has a rapid onset and is debilitating, it usually resolves quickly and does no serious harm.

\section{MATERIALS AND METHODS}

A survey was conducted by a questionnaire containing 10 questions was given to 100 dental students of different colleges. Their answers were taken and represented in the form of pie charts

\section{Questionnaire}

1) Are you aware of the disease ANUG?
a)Yes
b)No

2) How will you diagnose ANUG?
a)clinical examination
b) Radiographical examination
c) Clinical and microbial examination

$3)$ Which of the following is not the salient feature of ANUG?
A) Pharyngeal tissues affected
b) Without a significant odour
c) Lesions on buccal mucosa
d) Talking may be painful

4) How effective is detrimental treatment?
a) Less effective
b) More effective 
5) What are the chemical substances involved in rinse treatment?
a) Zinc sulphide \& calcium carbonate
b) Magnesium chloride \& Aluminium sulphate
c) Potassium permanganate \& Calcium fluoride
d) Hydrogen peroxide \&chlorhexidine

6) The ANUG disease is more common in patients of age?
a) 10 - 20 years
b) 21 - 30 years
c) 31 - 40 years
d) 41 - 50 years
e) Above 60

7) The ANUG disease is common in patients with disease
a) Fragile $X$ syndrome
b) Down's syndrome
c) Klinefelter syndrome
d) prader- Willi syndrome

8) What is the disease predispose to ANUG?
a) Syphilis \& cancer
b) Ulcerative colitis
c) Leukaemia \& anaemia
d) All the above

9) The ANUG disease is more common in
a) Infants
b) Children
c) Adults
d) Oldage people

10) What will happen if the disease is left untreated
a)Gingivitis
b) Trench mouth
c) Dental plaque
d) Necrotising ulcerative periodontitis

\section{RESULT}

In the above study it is known that $65 \%$ were aware of ANUG,Many students said that this disease is common in patients with disease Down's syndrome and many said this disease is common in children, Most of them are not aware of the management of ANUG disease

\section{DISCUSSION}

The awareness of this disease among the students was only about $65 \%$ and the remaining $35 \%$ are may or may not aware of this disease

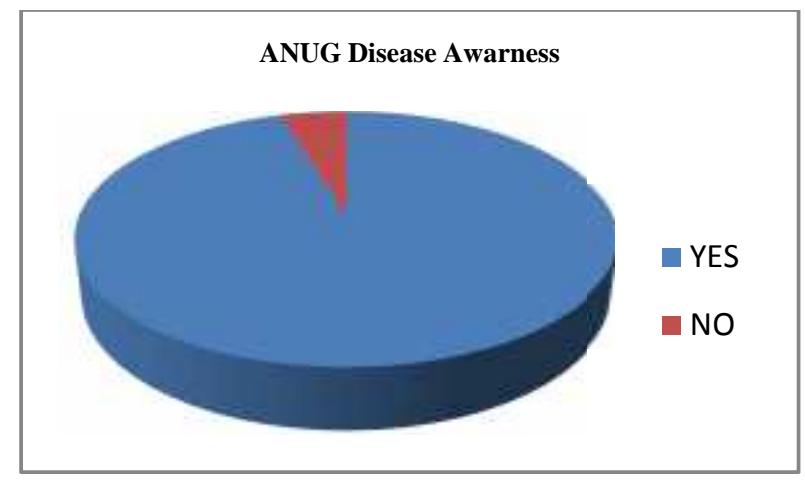

The major diagnosis of this known by the students is $19 \%$ rooted as clinical examination $43 \%$ said as radio graphical examination and the remaining $38 . \%$ said as clinical and the microbial examination.

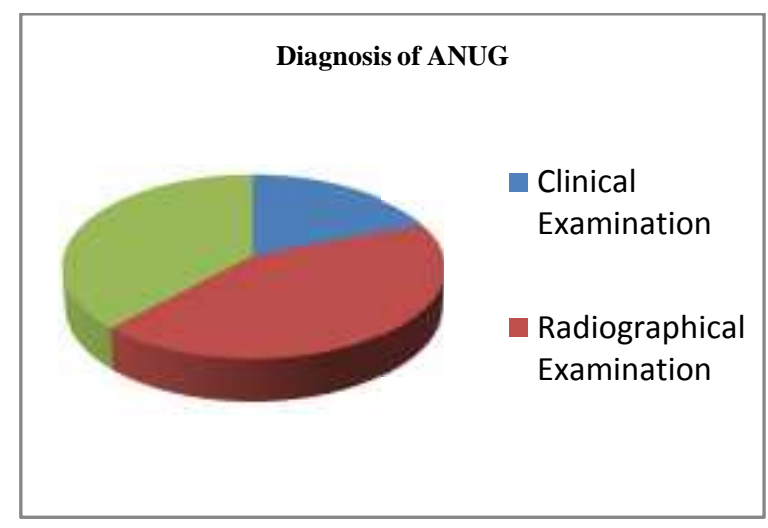

Th common salient feature of this disease is pharyngeal tissue affected, lesions on the buccal mucosa and Talking may be painful.

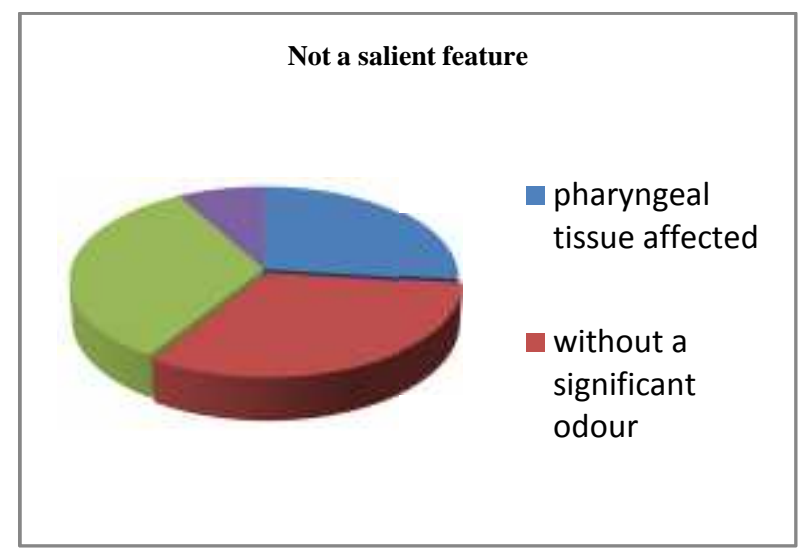

Debrimentis one of the most common treatment of this disease and $60 \%$ of the students reported that this treatment is more effective.

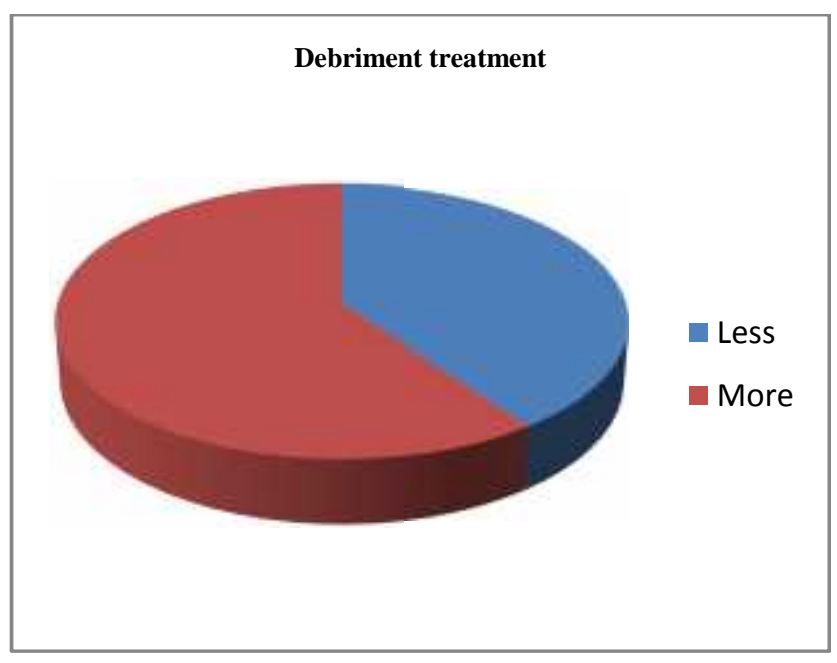


The main chemical substance which is used in the treatment of this disease is Hydrogen peroxide and chlorohexidine and only $24 \%$ were aware of that and many reported Zinc sulphide \& calcium carbonate $14 \%$, Magnesium chloride \& aluminium sulphate $26 \%$, Potassium permanganate \&calcium fluoride $36 \%$

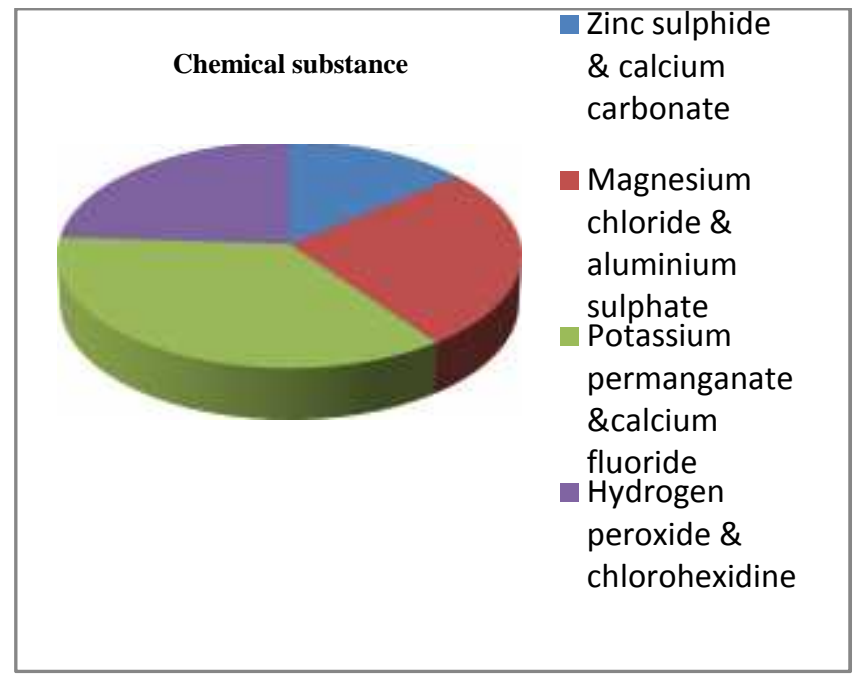

ANUG is common in the patient in the age group of 31-40 and most of them has reported correctly.

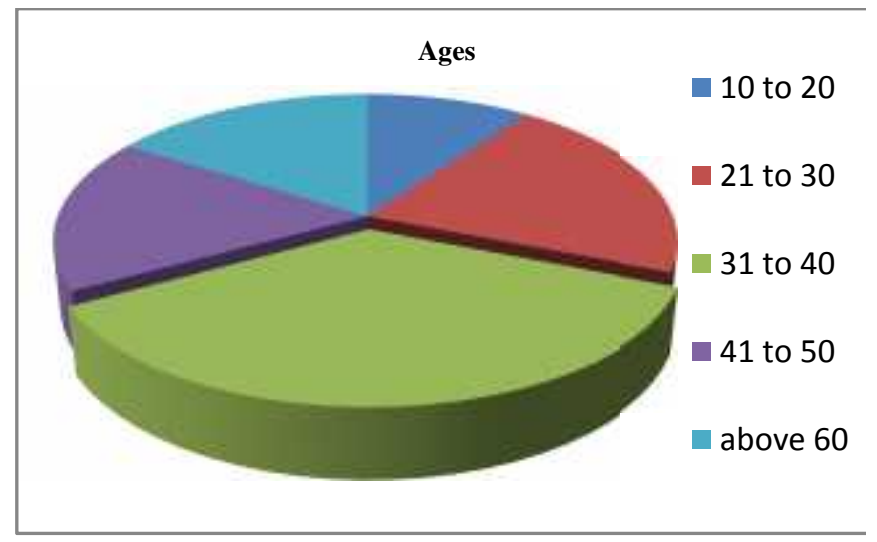

ANUG is common in the patients with the disease of Down's syndrome and $44 \%$ reported this.

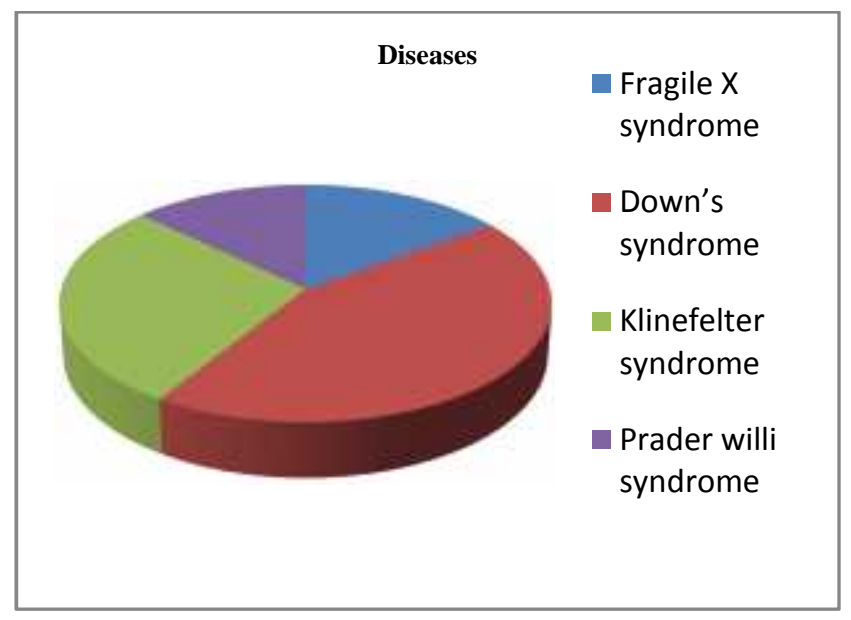

Disease which is predispose to ANUG are syphilis, cancer, ulcerative colitis, leukaemia and anaemia.

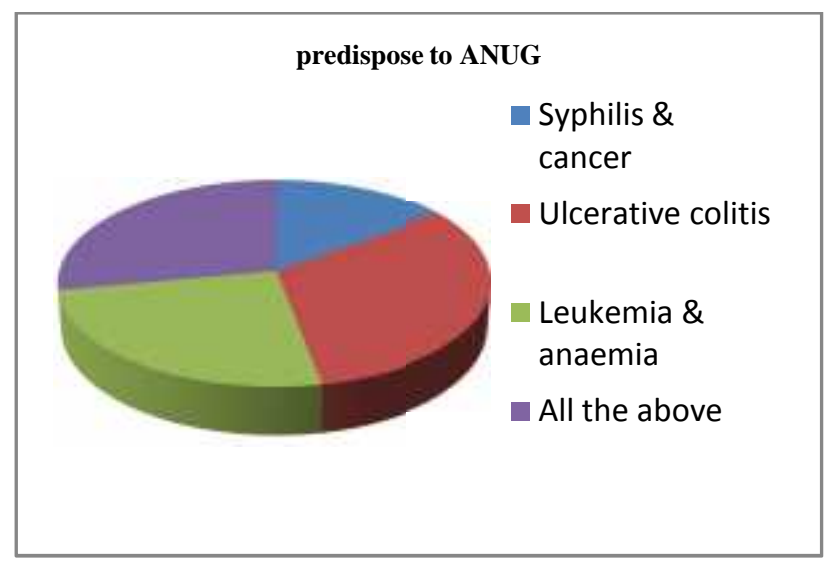

ANUG has been more common in the Adults, as these are prone to this disease very easily

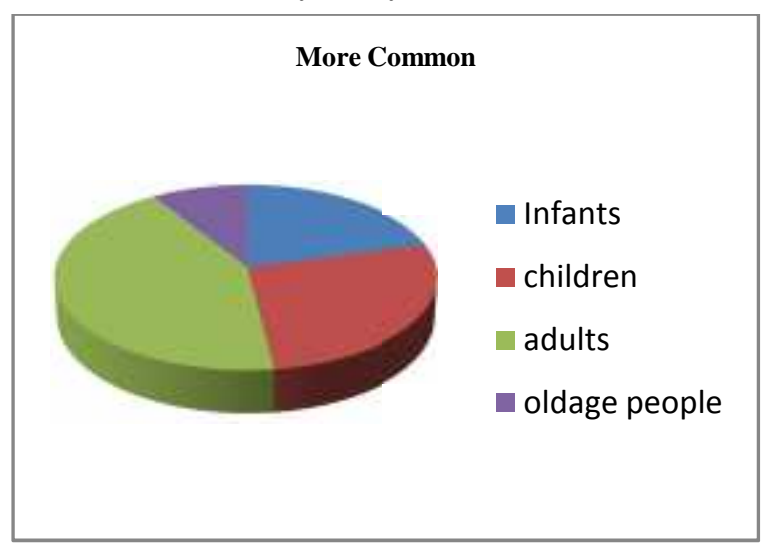

\section{CONCLUSION}

As ANUG belongs to one of the type of necrotising ulcer and it causes a severe complications if it is prolonged so we have to create the awareness of this disease. The knowledge and awareness levels about ANUG amongst the dental students seems to unclear and this study was initiated to explore this further. This study will further initiate the common causes and symptoms of this disease among the students. This is proven to be very helpful to create the awareness.

\section{References}

Pathogen-related spirochetes identified within gingival tissue from patients with acute necrotizing ulcerative gingivitis.,G R Riviere, K S Weisz, L G Simonson, and S A Lukehart

Acute necrotizing ulcerative gingivitis in college students Donald B. Giddon, D.M.D., Ph.D.,S. Jerome Zackin, D.M.D.,Paul Goldhaber, D.D.S.

NYS Department of Health AIDS Institute. "Clinical Manifestations and Management of HIV-Related Periodontal Disease". Oral Health Care for People with HIV Infection: HIV Clinical Guidelines. p. 31.

American Academy of Periodontology (1999). "Consensus report: Necrotizing Periodontal Diseases". Ann. Periodontol. 4 (1): 78. doi:10.1902/annals.1999.4.1.78

Taylor, FE; McKinstry, WH (1917). "The Relation of Peridental Gingivitis to Vincent's Angina." (PDF). 
Proceedings of the Royal Society of Medicine. 10

(Laryngol Sect): 43-8. PMC 2017821

Please cite this article in press as:

S.Vignesh et al (2017), Knowledge And Awareness Of Anug Among Dental Students, International Journal of Current Advanced Research, 6(3), pp. 2687-2690.

http://dx.doi.org/10.24327/ijcar.2017. 2690.0077 